\title{
B2 protein from betanodavirus is expressed in recently infected but not in chronically infected fish
}

\author{
Kjersti B. Mézeth ${ }^{1, *}$, Sonal Patel ${ }^{1,2}$, Håvard Henriksen ${ }^{1}$, Anne Marie Szilvay ${ }^{1}$, \\ Audun H. Nerland ${ }^{1,2,3}$ \\ ${ }^{1}$ Department of Molecular Biology, University of Bergen, Postbox 7803, 5020 Bergen, Norway \\ ${ }^{2}$ Institute for Marine Research, Postbox 1870 Nordnes, 5817 Bergen, Norway \\ ${ }^{3}$ Present address: The Gade Institute, University of Bergen, 5021 Bergen, Norway
}

\begin{abstract}
Betanodavirus infects both larvae and juvenile fish and can cause the disease viral encephalopathy and retinopathy (VER). During an acute outbreak of VER, infected individuals display several clinical signs of infection, i.e. abnormal swimming pattern and loss of appetite. Betanodaviruses can also cause chronic or persistent infection where the infected individuals show no clinical signs of infection. During infection the viral sub-genomic RNA3 and the RNA3-encoded B2 protein are expressed. Antibodies against the B2 protein from Atlantic halibut nodavirus were raised and used together with antibodies against the capsid protein to detect the presence of these 2 viral proteins in infected cells in culture and at different stages of infection in Atlantic halibut Hippoglossus hippoglossus and Atlantic cod Gadus morhua. The B2 protein was detected in recently infected, but not in chronically infected fish. Results suggest that the detection of B2 may be used to discriminate a recent and presumably active infection from a chronic and presumably persistent infection.
\end{abstract}

KEY WORDS: Fish nodavirus · Atlantic halibut $\cdot$ Atlantic cod $\cdot$ B2 protein $\cdot$ Viral nervous necrosis Resale or republication not permitted without written consent of the publisher

\section{INTRODUCTION}

The Nodaviridae family includes viruses of the genus Alphanodavirus, which infect insects, and of the genus Betanodavirus, which infect fish (Munday et al. 2002, Venter \& Schneemann 2008). Betanodaviruses are neurotrophic and affect the retina, the central nervous system and the ganglia of the peripheral nervous system. Infection results in lesions characterized by cellular vacuolation and neuronal degeneration, the disease called viral nervous necrosis (VNN) or viral encephalopathy and retinopathy (VER). The disease particularly affects larvae and juvenile fish, causing mortality rates up to $100 \%$, and has been a major obstacle for successful farming of several fish species (Grotmol et al. 1997, Lin et al. 2001, Munday et al. 2002). During acute outbreaks, high numbers of viruses are released into the environment (Nerland et al. 2007). Fish larvae are susceptible to the virus in the environment, indicating the possibility of horizontal transmission (Grotmol et al. 1999). Survivors of an outbreak can become subclinical carriers when the virus persists in the nervous system for a long period of time (Johansen et al. 2004). This may lead to vertical transmission, as the virus may be reactivated during sexual maturation. Betanodaviruses are small, naked icosahedral viruses with a capsid composed of multiple units of a single protein, the capsid protein (Delsert et al. 1997). The genome consists of 2 positive RNA strands, RNA1 and RNA2, which are capped but not polyadenylated (Sommerset \& Nerland 2004). RNA1 encodes the viral RNA dependent RNA polymerase (RdRp) whereas RNA2 encodes the capsid protein (Tan et al. 2001, Sommerset \& Nerland 2004). During RNA replication, a sub-genomic RNA segment called RNA3 is synthesized from the 3' region of RNA1 (Nagai \& Nishizawa 1999). RNA3 encodes a polypeptide called B2, which is essential 
for both alpha- and betanodavirus replication (Johnson et al. 2004, Fenner et al. 2006b).

RNA interference (RNAi) is a conserved evolutionary mechanism widely found in nature and is considered to be a cellular defense mechanism against foreign genes and viral infection (Cullen 2002, Plasterk 2002). The B2 proteins from the alphanodaviruses Flock House virus (FHV) and Nodamura virus (NoV) and the betanodavirus greasy grouper nervous necrosis virus (GGNNV) have been shown to suppress RNAi by binding to double stranded RNA, thus preventing cleavage, leading to enhanced accumulation of viral RNAs in plant, insect and mammalian cells (Johnson et al. 2004, Lingel et al. 2005, Sullivan \& Ganem 2005, Fenner et al. 2006a).

Atlantic halibut nodavirus (AHNV) was first isolated from hatchery-reared larvae of Atlantic halibut in 1995 (Grotmol et al. 1995). The clinical signs of AHNV infection are loss of appetite, abnormal swimming pattern, and changes in pigmentation (Munday et al. 2002). Mass mortality in farmed Atlantic cod and diseased juveniles with similar clinical signs to AHNV-infected Atlantic halibut led to the identification of Atlantic cod nodavirus (ACNV) (Patel et al. 2007, Nylund et al. 2008). The RdRp and capsid protein of AHNV and ACNV are more than $97 \%$ identical (GenBank accession nos. AJ401165, AJ245641, EF617332, EF617326), and both strains belong to the barfin flounder genotype of nodavirus (Nishizawa et al. 1997). Diagnosis of VER is performed by histopathology with identification of necrosis and vacuolation in the brain and retina, often combined with immunohistochemistry (IHC) using antibodies against the capsid protein (Grotmol et al. 1997). Other diagnostic tests, including enzyme-linked immunosorbant assays (ELISA) and reverse transcriptase polymerase chain reactions (RT-PCR) for detection of the capsid protein and viral RNAs, respectively, have been developed (World Organisation for Animal Health 2006). In the present study we found that the capsid protein was detected in both recently infected fish and in chronically infected fish, whilst the B2 protein was only detected in recently infected fish. This suggests that detection of B2 expression can be used to discriminate between different stages of nodavirus infection.

\section{MATERIALS AND METHODS}

Sequence analysis. The deduced amino acid sequences (GenBank, NCBI, Accession numbers AF319555 and NOD401165) were compared using the ClustalX1.83 software, applying standard default parameters.
Plasmids. Total RNA was isolated from brain tissue of Atlantic halibut infected by AHNV and transcribed to cDNA for use as a template in a PCR reaction with the primers 5'-CAC CAT GGA ACA AAT CCA ACA GGC3' and 5'-TAC ACG GGA GTG CGA CGT TGT CTG-3'. The 276 bp PCR product was cloned into the pET200/ D-Topo vector (Invitrogen) creating a plasmid encoding a B2 protein with a $6 \mathrm{xHis}$ tag; the resulting plasmid was named pETB2-His. Using pCMV-RNA1-myc (Mézeth et al. 2007) as the template and the primers 5'-GCG GCC GCA TAC TCT GTC TCC ATC GGC T-3' and 5'-AAA CTG ACA ACC ATG GAA CA-3', a plasmid expressing Myc-tagged B2 protein from a eukaryotic promoter was constructed. The B2 stop codon TAG was changed to TAT, followed by cloning of the $248 \mathrm{bp}$ fragment with NCoI and NotI overhangs into the NCoI and Not I sites in the $\mathrm{pCMV} / \mathrm{myc} / \mathrm{cyto}$ vector (Clontech). The resulting plasmid was named pcB2-Myc. Constructions were confirmed by DNA sequencing.

Expression and purification of His-tagged B2. Recombinant B2-His was expressed from the pETB2-His vector in Escherichia coli. The protein was purified on a fast protein liquid chromatography (FPLC) system (Amersham Pharmacia) using a modified, scaled up, Ni-NTA procedure (Qiagen) on a HiTrap chelating column (Amersham) loaded with copper. Recombinant B2His protein was dialyzed against phosphate-buffered saline (PBS) and concentrated using PEG6000.

Cell lines, infection and transfection. The fibroblast cell line (SSN-1) from whole fry tissue of striped snakehead Channa striatus was infected with AHNV (Frerichs et al. 1996). The cells were grown on poly-Llysine coated coverslips in a 24 -well plate and infected as described previously (Mézeth et al. 2007). COS-7 cells were transfected with Lipofectamine 2000 (Gibco) using $0.25 \mu \mathrm{g}$ plasmid DNA and $1.25 \mu \mathrm{l}$ Lipofectamine 2000 per coverslip.

Antibodies. Purified recombinant His-tagged B2 protein was used for immunization of rabbits. BioGenes (Berlin) performed immunization and testing of the rabbit serum (rabbit anti-B2 6073) by ELISA. Before use the serum was diluted $1 / 10$ in PBS and absorbed against COS-7 cells. The monoclonal antibody 9E10 (IgG1) recognizes the c-Myc epitope (Evan et al. 1985). A mouse anti-capsid serum was raised by immunizing mice with purified His-tagged recombinant capsid protein, and testing of the serum was done by ELISA (Jordal 2004). The rabbit anti-capsid serum was described previously (Sommerset et al. 2005). For immunofluorescence (IF) analysis of sections and transfected and infected cells, all primary and secondary (Texas Red and fluorescein isothiocyanate [FITC] conjugated species-specific from Southern Biotechnology) antibodies were diluted in $0.5 \%$ BSA in PBS. 
Sampling of virus-infected fish tissue. AHNVinfected Atlantic halibut were sampled from 2 groups. One group consisted of larvae hatched and cultivated in 6-well Nunc plates. The larvae were infected with AHNV using homogenates prepared from infected halibut brains (diluted 1/100) as described previously (Grotmol et al. 1999). The larvae were sampled 10 to $15 \mathrm{~d}$ post-infection while mortality was observed. This group is further referred to as 'recently infected'. The other group of Atlantic halibut consisted of survivors of a natural VER outbreak (during larval stage) at a commercial sea farm. The fish were obtained from the same group that has been described previously (Johansen et al. 2004). The samples used in the present study were taken from $270 \mathrm{~g}$ fish 12 mo after the VER outbreak. This group is further referred to as 'chronically infected'. Larvae used as a negative control were taken from a group that had previously been found negative for presence of nodavirus using RT-PCR amplification with R3 and F2 primers (Nishizawa et al. 1994, Grotmol et al. 1999).

ACNV-infected Atlantic cod were sampled from 2 groups. One group of juvenile cod, found to be ACNVnegative by real-time PCR screening, were given an intramuscular injection with $100 \mu \mathrm{l}$ of a homogenate solution prepared from infected brain tissue. Six weeks after infection, brain samples were collected from the eye and brain tissues and analyzed as described previously (Patel et al. 2007). No clinical signs of VER or mortality were observed during the $6 \mathrm{wk}$. This group is further referred to as 'recently infected'. The second group of Atlantic cod consisted of survivors from a natural VER outbreak described previously (Patel et al. 2007). The brain samples used in the present study were taken 15 mo after outbreak of VER and the weight of the fish varied from 150 to $1000 \mathrm{~g}$.

Immunofluorescence analysis. Transfected or infected cells were fixed in $4 \%$ formaldehyde and permeabilized by methanol treatment. IF analysis was performed as described previously (Szilvay et al. 1999). For detection of the B2 and capsid proteins, pri- mary antibodies anti-B2 6073 and the mouse anti-capsid serum were used. Labeled cells were examined for fluorescence and images were captured using the Leica DM RXA confocal scanning microscope with a 63x oil immersion objective and Leica PowerScan software. Sections of brain and eye from non-infected, chronically or recently infected fish were subjected to IF analysis. After rehydrating, sections were blocked with $0.5 \%$ BSA in PBS for 15 min at room temperature. Primary antibody (anti-B2 6073 or anti-capsid K233) was added to the sections and incubated overnight at $4{ }^{\circ} \mathrm{C}$. Sections were washed carefully 5 times with PBS before FITC-labeled secondary antibody was added and incubated for $1 \mathrm{~h}$ in the dark at room temperature. Prior to being mounted on a coverslip using Slowfade (Molecular Probes), sections were washed 5 times with PBS and once with distilled water. Images were captured using a Leica DM6000-B and LAS software.

\section{RESULTS}

\section{Sequence comparison}

The amino acid sequence of B2 from AHNV, which is identical with the amino acid sequence of B2 from ACNV, was compared with the B2 amino acid sequence from GGNNV (see Fig. 5). The sequence showed an identity of $84 \%$ and a similariry of $89 \%$.

\section{Characterization of anti-B2 6073}

IF analysis of COS-7 cells expressing B2-Myc using anti-B2 6073 together with monoclonal anti-Myc 9E10 showed overlapping staining of the 2 antibodies, demonstrating that the 2 antibodies recognized the same fusion protein (Fig. 1). This was confirmed by Western blot analysis of recombinant B2-His with antiB2 6073 and monoclonal anti-His, which detected a band of similar size (data not shown).
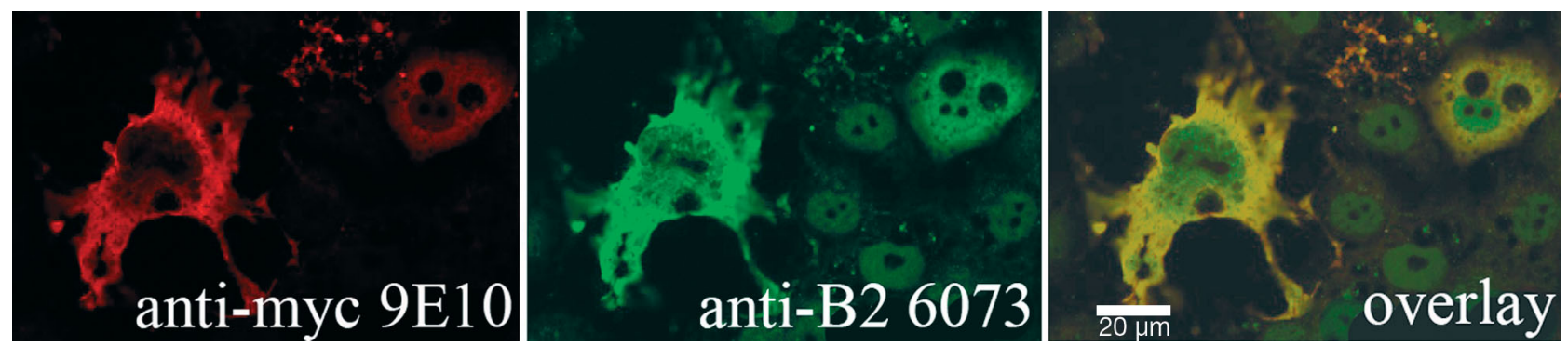

Fig. 1. Detection of B2-myc protein in transfected COS-7 cells by immunofluorescence analysis using monoclonal mouse anti-myc 9E10 (undiluted hybridoma medium) and rabbit anti-B2 serum 6073 (1/600) combined with secondary antibodies Texas Red-labeled anti-mouse (1/100) and FITC-labeled anti-rabbit (1/50). Scale bar same for all panels 


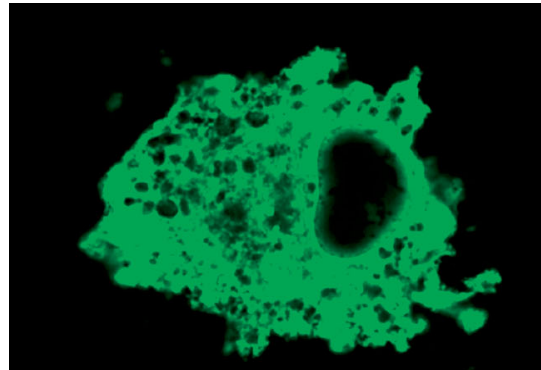

\section{anti-B2 6073}
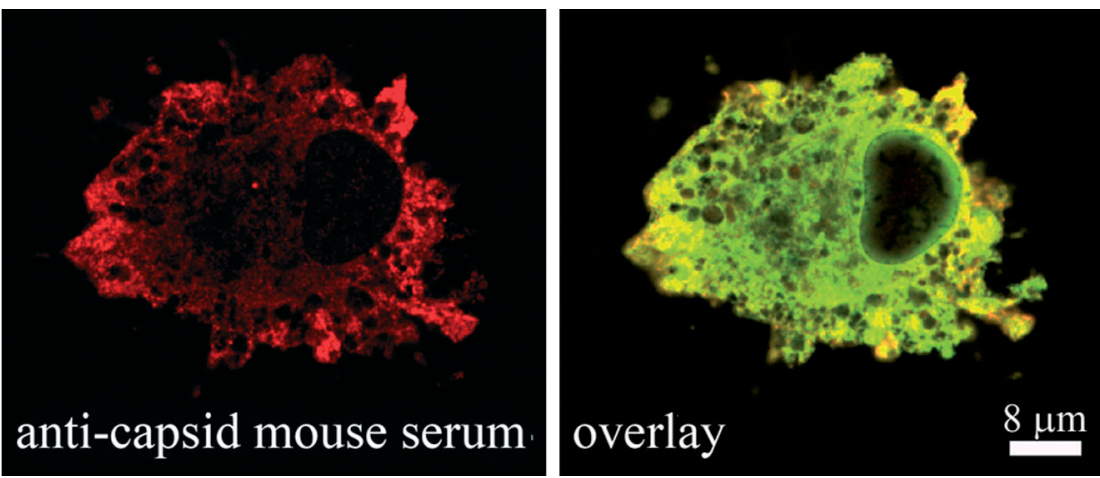

Fig. 2. Detection of B2 and the capsid protein in Atlantic halibut nodavirus (AHNV) infected SSN-1 cells using rabbit anti-B2 6073 $(1 / 1600)$ and anti-capsid mouse serum (1/100) combined with secondary antibodies Texas Red-labeled anti-mouse (1/100) and FITC-labeled anti-rabbit (1/50). Scale bar same for all panels

\section{Detection of B2 in infected SSN-1 cells}

In order to establish if the B2 protein is expressed during AHNV infection in SSN-1 cells, we performed an immunofluorescence double labeling experiment using anti-B2 6073 and anti-capsid mouse serum. B2 was detected $18 \mathrm{~h}$ after infection and the expression levels increased as more cells were infected (data not shown). Fig. 2 shows an example of an AHNV-infected cell and demonstrates that the $\mathrm{B} 2$ protein was indeed expressed and that both viral proteins were localized to the cytoplasm. While the B2 protein was detected evenly in the cytoplasm, the capsid protein was more concentrated along the cellular membrane.

\section{Detection of B2 and the capsid protein in infected halibut and cod}

The antibodies anti-B2 6073 and anticapsid K233 were then used to compare expression of B2 and capsid proteins in the brains of infected Atlantic halibut and Atlantic cod at different times after infection. IF analysis of AHNV-infected Atlantic halibut using the antibodies showed that the capsid protein was present in both recently and chronically infected halibut, while the $\mathrm{B} 2$ protein was only detected in recently infected halibut (Fig. 3). Both the capsid and B2 proteins were located in the cytoplasm of the cells (Fig. 3). IF analysis of chronically and recently ACNV-infected Atlantic cod showed similar results as found for AHNV-infected Atlantic halibut (Fig. 4): both the capsid and B2 proteins were detected in recently infected fish, whereas only the capsid protein was detected in chronically infected fish.

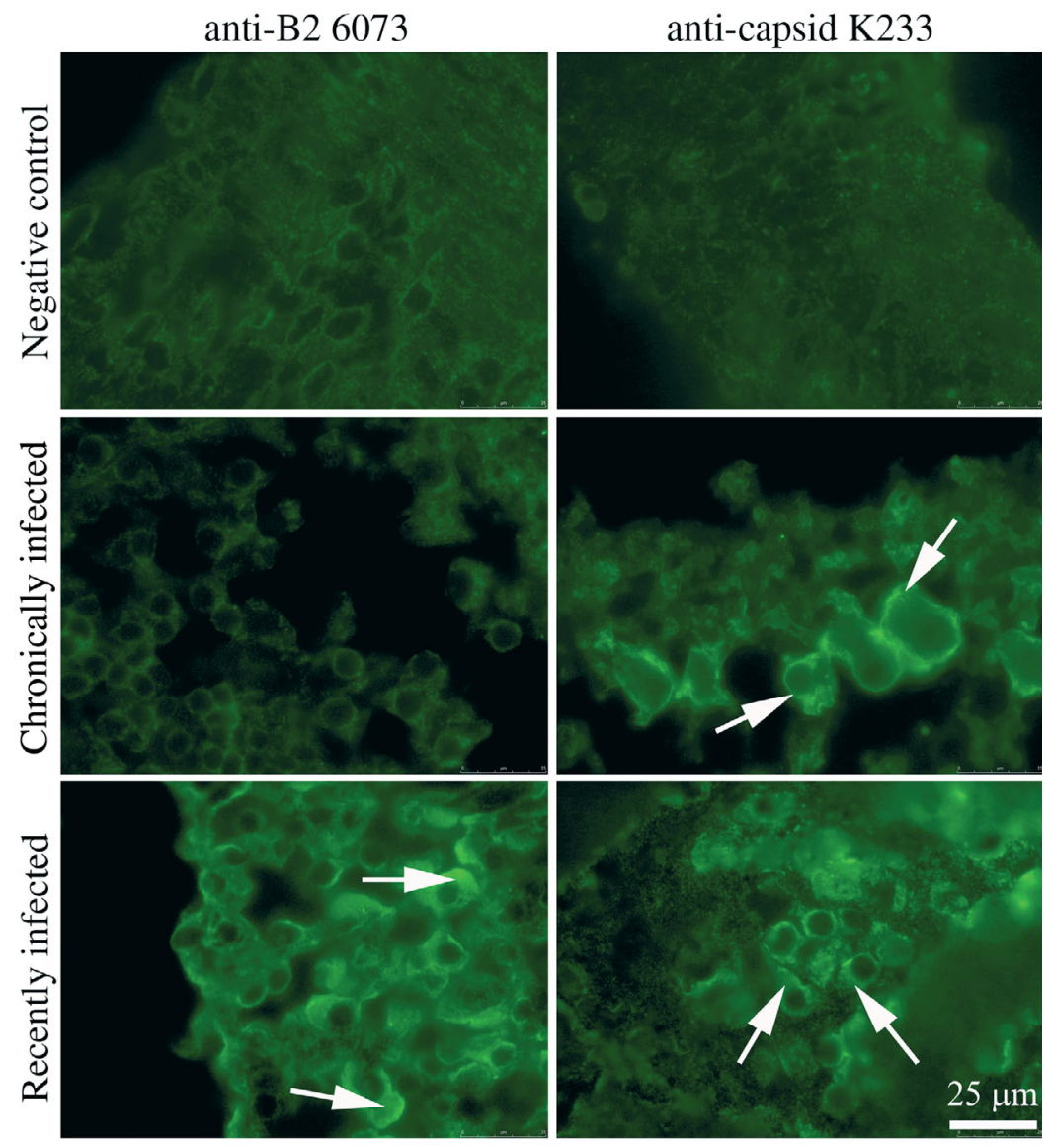

Fig. 3. Hippoglossus hippoglossus. Immunofluorescence analysis detecting the presence of B2 and capsid protein in brain tissue of recently and chronically Atlantic halibut nodavirus (AHNV)-infected individuals of Atlantic halibut. AntiB2 6073 (1/1200) and anti-capsid K233 (1/400) were combined with FITC-labeled anti-rabbit (1/100) for detecting the viral proteins. Arrows: cells positive for viral proteins. Scale bar same for all panels 


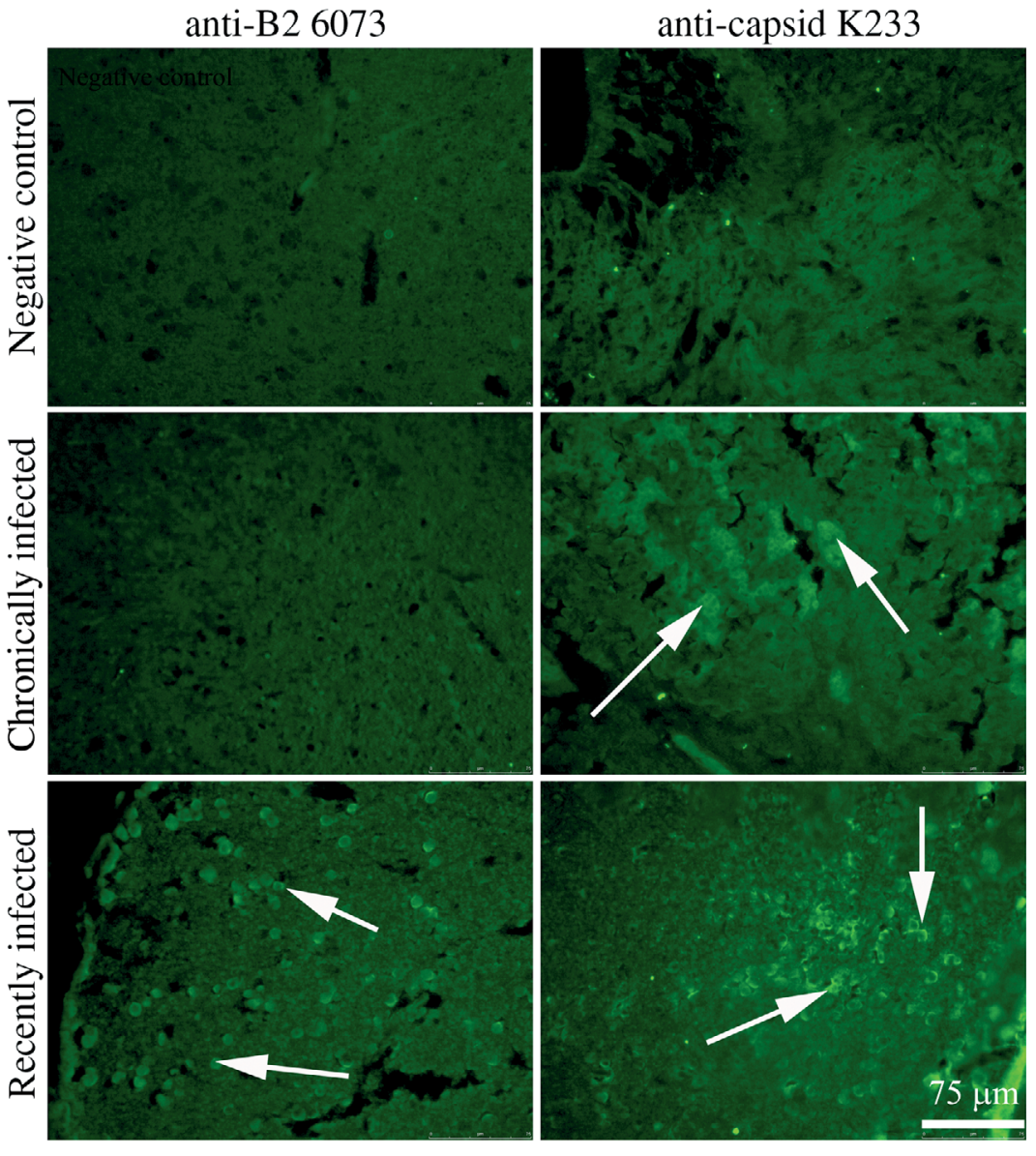

Fig. 4. Gadus morhua. Immunofluorescence analysis detecting the presence of B2 and capsid proteins in brain tissue of recently and chronically Atlantic cod nodavirus (ACNV)-infected Atlantic cod. Rabbit anti-B2 6073 (1/1200) and anti-capsid K233 (1/400) were combined with secondary antibody FITC-labeled anti-rabbit (1/100). Arrows: cells positive for viral proteins. Scale bar same for all panels

\section{DISCUSSION}

Some betanodavirus infections can develop into a state where the virus is present in the host but is not causing clinical disease (Johansen et al. 2002). The pathological signs of a persistent infection differ from acute outbreaks of VNN. In persistently infected halibut, large macrophage-like cells containing virus can be found in the retina and brain where nodavirus-positive cells are usually restricted to growth cones (Johansen et al. 2002). In an acute infection, nodavirus- infected cells are distributed throughout the entire brain and eye tissue except in the growth cones (Grotmol et al. 1999). Using the anti-B2 6073 serum, AHNV B2 protein was detected in both transfected and infected cells. Interestingly, the distribution was similar in both mammalian and fish cells. Furthermore, results showed that the specificity of anti-B2 6073 is not restricted to the recombinant protein B2-His used for immunization. The B2 protein from FHV, NoV and GGNNV has been found to inhibit RNAi (Guo \& Ding 2002, Li et al. 2002, Fenner et al. 2006b, Fenner et al. 2007). This was not shown specifically for AHNV B2 in the present study. The sequence similarity between GGNNV B2 and B2 from AHNV indicates, however, that the proteins could possess the same role in fighting cellular anti-viral defense mechanisms (Fig. 5). Antibodies developed against recombinant capsid and B2 proteins from Atlantic halibut nodavirus also recognized the corresponding viral proteins from Atlantic cod nodavirus, confirming that the 2 viruses are closely related (Nylund et al. 2008). Current diagnostic methods for nodavirus detection (RT-PCR, ELISA and IHC) are all based on the detection of virus components. RTPCR detects viral RNA, whereas ELISA and IHC detect the capsid protein. In the present study we tested for the presence of the viral capsid protein and the B2 protein in recently and chronically infected fish. Samples of larvae and juveniles that have been infected with nodavirus were defined as recently infected when samples were taken within weeks, during or before clinical signs or mortality were observed. Larger fish that had survived a natural outbreak of nodavirus but had been without clinical signs or mortality for 12 to 15 mo were defined as chronically infected. These fish had been screened positive for nodavirus using PCR techniques. The

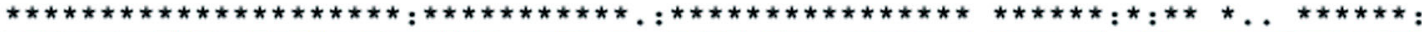 AHNNV MEQIQQAIDQHLVELEQLFQVLMDTRVALGGVTVVQVNEMRTFVISAHAAACRLHVLSHRYPPPPVAGEEPMETE GGNNV MEQIQQAIDQHLVELEQLFQVMMDTRVALGGVTAIQVNEMRTFVISAHAAARRLHVLSRRFPPLPAVIEEPMETD}

Fig. 5. Amino acid sequence alignment of protein B2 from Atlantic halibut nodavirus (AHNV) and greasy grouper nervous necrosis virus (GGNNV) using ClustalX1.83. (*) Identical residues; (:) residues that are strongly conserved; (.) residues with weakly conserved chemical properties. White $=$ sites where there is no conservation; light turquoise: hydrophobic residues; purple: acidic residues; green: hydrophilic residues; other colors as in the ClustalX1.83 standard color scheme 
chronically infected Atlantic halibut had previously been found to be persistently infected (Johansen et al. 2004), and presumably this was also the case for chronically infected Atlantic cod. Our results showed that by analyzing for presence of the B2 protein it is possible to discriminate between early and late stages of nodavirus infection. This will be useful in epidemiological studies, as it can be determined if the viral agent has infected a fish population recently or long ago. Long-term studies with sequential samplings must be conducted to elucidate at what time during infection the expression of B2 declines.

Acknowledgements. The authors thank I. U. Fiksdal for excellent technical assistance and R. Cox for reading of the manuscript. The study was supported by the University of Bergen and grants from The Faculty of Mathematics and Natural Sciences, University of Bergen.

\section{LITERATURE CITED}

> Cullen BR (2002) RNA interference: antiviral defense and genetic tool. Nat Immunol 3:597-599

> Delsert C, Morin N, Comps M (1997) A fish encephalitis virus that differs from other nodaviruses by its capsid protein processing. Arch Virol 142:2359-2371

> Evan GI, Lewis GK, Ramsay G, Bishop JM (1985) Isolation of monoclonal antibodies specific for human c-myc protooncogene product. Mol Cell Biol 5:3610-3616

Fenner BJ, Goh W, Kwang J (2006a) Sequestration and protection of double-stranded RNA by the betanodavirus B2 protein. J Virol 80:6822-6833

Fenner BJ, Thiagarajan R, Chua HK, Kwang J (2006b) Betanodavirus B2 is an RNA interference antagonist that facilitates intracellular viral RNA accumulation. J Virol 80: 85-94

> Fenner BJ, Goh W, Kwang J (2007) Dissection of doublestranded RNA binding protein B2 from betanodavirus. J Virol 81:5449-5459

Frerichs GN, Rodger HD, Peric Z (1996) Cell culture isolation of piscine neuropathy nodavirus from juvenile sea bass, Dicentrarchus labrax. J Gen Virol 77:2067-2071

Grotmol S, Totland GK, Kvellestad A, Fjell K, Olsen AB (1995) Mass mortality of larval and juvenile hachery-reared halibut (Hippoglossus hippoglossus L.) associated with the presence of virus-like particles in the central nervous system and retina. Bull Eur Assoc Fish Pathol 15:176-180

Grotmol S, Totland GK, Thorud K, Hjeltnes BK (1997) Vacuolating encephalopathy and retinopathy associated with a nodavirus-like agent: a probable cause of mass mortality of cultured larval. Dis Aquat Org 50:161-169

> Grotmol S, Bergh O, Totland GK (1999) Transmission of viral encephalopathy and retinopathy (VER) to yolk-sac larvae of the Atlantic halibut Hippoglossus hippoglossus: occurrence of nodavirus in various organs and a possible route of infection. Dis Aquat Org 36:95-106

> Guo HS, Ding SW (2002) A viral protein inhibits the long range signaling activity of the gene silencing signal. EMBO J 21:398-407

> Johansen R, Ranheim T, Hansen MK, Taksdal T, Totland GK (2002) Pathological changes in juvenile Atlantic halibut Hippoglossus hippoglossus persistently infected with nodavirus. Dis Aquat Org 50:161-169
Johansen R, Grove S, Svendsen AK, Modahl I, Dannevig B (2004) A sequential study of pathological findings in Atlantic halibut, Hippoglossus hippoglossus (L.), throughout one year after an acute outbreak of viral encephalopathy and retinopathy. J Fish Dis 27:327-341

Johnson KL, Price BD, Eckerle LD, Ball LA (2004) Nodamura virus nonstructural protein B2 can enhance viral RNA accumulation in both mammalian and insect cells. J Virol 78:6698-6704

Jordal S (2004) A study of the Atlantic halibut nodavirus capsid protein. Master's thesis, Department of Molecular Biology, University of Bergen

Li H, Li WX, Ding SW (2002) Induction and suppression of RNA silencing by an animal virus. Science 296:1319-1321

Lin L, He JG, Mori K, Nishioka T and others (2001) Mass mortalities associated with viral nervous necrosis in hatcheryreared groupers in the People's Republic of China. Fish Pathol 36:186-188

Lingel A, Simon B, Izaurralde E, Sattler M (2005) The structure of the flock house virus B2 protein, a viral suppressor of RNA interference, shows a novel mode of double-stranded RNA recognition. EMBO Rep 6: 1149-1155

Mézeth KB, Nylund S, Henriksen H, Patel S, Nerland AH, Szilvay AM (2007) RNA-dependent RNA polymerase from Atlantic halibut nodavirus contains two signals for localization to the mitochondria. Virus Res 130:43-52

Munday BL, Kwang J, Moody N (2002) Betanodavirus infections of teleost fish: a review. J Fish Dis 25:127-142

- Nagai T, Nishizawa T (1999) Sequence of the non-structural protein gene encoded by RNA1 of striped jack nervous necrosis virus. J Gen Virol 80:3019-3022

Nerland AH, Skaar C, Eriksen TB, Bleie H (2007) Detection of nodavirus in seawater from rearing facilities for Atlantic halibut Hippoglossus hippoglossus larvae. Dis Aquat Org 73:201-205

> Nishizawa T, Mori K, Nakai T, Furusawa I, Muroga K (1994) Polymerase chain reaction (PCR) amplification of RNA of striped jack nervous necrosis virus (SJNNV). Dis Aquat Org 18:103-107

> Nishizawa T, Furuhashi M, Nagai T, Nakai T, Muroga K (1997) Genomic classification of fish nodaviruses by molecular phylogenetic analysis of the coat protein gene. Appl Environ Microbiol 63:1633-1636

> Nylund A, Karlsbakk E, Nylund S, Isaksen TE and others (2008) New clade of betanodaviruses detected in wild and farmed cod (Gadhus morhua) in Norway. Arch Virol 153:541-547

Patel S, Korsnes K, Bergh A, Vik-Mo F, Pedersen J, Nerland $\mathrm{AH}$ (2007) Nodavirus in farmed Atlantic cod Gadus morhua in Norway. Dis Aquat Org 77:169-173

> Plasterk RH (2002) RNA silencing: the genome's immune system. Science 296:1263-1265

> Sommerset I, Nerland AH (2004) Complete sequence of RNA1 and subgenomic RNA3 of Atlantic halibut nodavirus (AHNV). Dis Aquat Org 58:117-125

> Sommerset I, Skern R, Biering E, Bleie H, Fiksdal IU, Grove S, Nerland AH (2005) Protection against Atlantic halibut nodavirus in turbot is induced by recombinant capsid protein vaccination but not following DNA vaccination. Fish Shellfish Immunol 18:13-29

Sullivan CS, Ganem D (2005) A virus-encoded inhibitor that blocks RNA interference in mammalian cells. J Virol 79: 7371-7379

Szilvay AM, Boe SO, Kalland KH (1999) Co-expression of a trans-dominant negative mutant of the human immunodeficiency virus type 1 (HIV-1) Rev protein affects the Rev- 
dependent splicing pattern and expression of HIV-1 RNAs. J Gen Virol 80:1965-1974

Tan C, Huang B, Chang SF, Ngoh GH, Munday B, Chen SC, Kwang J (2001) Determination of the complete nucleotide sequences of RNA1 and RNA2 from greasy grouper (Epinephelus tauvina) nervous necrosis virus, Singapore strain. J Gen Virol 82:647-653

Editorial responsibility: Mark Crane, Geelong, Victoria, Australia
Venter PA, Schneemann A (2008) Recent insights into the biology and biomedical applications of Flock House virus. Cell Mol Life Sci 65:2675-2687

World Organisation for Animal Health (2006) Manual of diagnostic tests for aquatic animals. OIE, Paris. Available at: www.oie.int/eng/normes/fmanual/A_summry. htm?e1d11

Submitted: May 6, 2008; Accepted: November 18, 2008 Proofs received from author(s): February 2, 2009 